\title{
Framework of the Virtual Construction Simulator 3 for construction planning and management education
}

Article

Accepted Version

Lee, S., Nikolic, D. and Messner, J. I. (2014) Framework of the Virtual Construction Simulator 3 for construction planning and management education. Journal of Computing in Civil Engineering, 29 (2). 05014008. ISSN 1943-5487 doi: https://doi.org/10.1061/(ASCE)CP.1943-5487.0000388 Available at https://centaur.reading.ac.uk/67432/

It is advisable to refer to the publisher's version if you intend to cite from the work. See Guidance on citing.

To link to this article DOI: http://dx.doi.org/10.1061/(ASCE)CP.19435487.0000388

Publisher: American Society of Civil Engineers

All outputs in CentAUR are protected by Intellectual Property Rights law, including copyright law. Copyright and IPR is retained by the creators or other copyright holders. Terms and conditions for use of this material are defined in the End User Agreement.

www.reading.ac.uk/centaur 


\section{CentAUR}

Central Archive at the University of Reading

Reading's research outputs online 


\title{
CP0934
}

\section{Framework of the Virtual Construction Simulator 3 for Construction Planning and Management Education}

\author{
Sanghoon Lee ${ }^{1}$, Dragana Nikolic, A.M. ASCE ${ }^{2}$, John I. Messner, M. ASCE ${ }^{3}$
}

\begin{abstract}
Teaching construction planning and management is challenging, as construction projects are dynamic due to many varying and unforeseen factors. A growing number of construction-related simulations and games demonstrate the benefits of providing students with a realistic and interactive learning experience for knowledge applicable in real world situations. Currently, the majority of construction simulation games focus on teaching managerial skills either at an organizational level, or very specific project-based activities. To encourage broader adoption of simulation games for construction planning and management education, this research effort outlines a framework for the development of the Virtual Construction Simulator (VCS) game as an open-source, customizable and expandable simulation for different learning scenarios. The VCS prototype uses a small pavilion case study to teach students the decisions involved in planning, and subsequently managing the project construction affected by varying factors such as weather and labor productivity. The current prototype has been evaluated for its usability and effectiveness as a learning tool with over two hundred students in undergraduate and graduate-level courses, demonstrating benefits in engaging students in learning the challenges and risks
\end{abstract}

\footnotetext{
${ }_{1}$ Ph.D., Architectural Engineering Department, Pennsylvania State University, 104 Engineering Unit A, University Park, PA 16802 U.S.A. Email: SHLatPSU@gmail.com

2 Ph.D., Lecturer, School of Construction Management and Engineering, University of Reading, UK. Email: d.nikolic@reading.ac.uk

3 Ph.D., Professor, Architectural Engineering Department, Pennsylvania State University, 104

Engineering Unit A, University Park, PA 16802 U.S.A. Email: jmessner@engr.psu.edu
} 
in efficient construction planning and management. The paper outlines the VCS development framework, the system architecture, and the functionality based on the defined learning objectives. Evaluation results and future development steps are also discussed.

KEYWORDS: Simulation Game, Development Framework, Construction Education, System Architecture

\section{INTRODUCTION}

Construction projects are dynamic and are affected by varying factors. Complex relationships between project cost, schedule, weather, laborers' productivity and resource availability that affect the project progress are difficult to grasp for students who lack industry experience. Understanding the logic of construction planning and the ability to manage various risks and factors affecting the construction schedules have become important for graduates entering the workforce, but also more challenging to support with traditional teaching approaches.

Teaching construction related concepts is still predominantly lecture-based with valuable, yet insufficient, site visits when available. Lectures are primarily a one-way knowledge transfer from the instructor to students; a passive approach in which instructors commonly encounter difficulties to evaluate each student's level of understanding during the class. Site visits are valuable since they allow students to experience real construction projects, but they are time constrained and thus do not expose students to all aspects of 
the construction of a project. Computer applications are also used in classes as a supplemental tool for students to exercise. While they are useful, the learning paradigm has not been changed.

Much research has focused on developing interactive simulation-based learning environments to better engage students. These learner-centered educational simulations provide risk-free testing of different scenarios and start to bridge the gap between the theoretical and knowledge applicable on real projects. The Virtual Construction Simulator (VCS) development project is a research effort that aimed to engage students in the interactive planning and management process of a construction project (Wang and Messner 2007; Nikolic et al. 2009). This paper presents a development framework for the third generation of the VCS (VCS3) - a continuing effort to develop a comprehensive simulation game for students to learn the decisions involved in planning and managing the project construction affected by the dynamic factors. Based on the lessons learned from previous VCS and educational application development efforts, specific simulation and game attributes were identified and aligned with the learning objectives for the VCS3. A system architecture was developed to correspond to the defined simulation game functional requirements and structured to allow for custom projects and learning scenarios to eventually support broader adoption. The VCS3 has been evaluated with both undergraduate and graduate students in the Department of Architecture Engineering for its functionality and learning effectiveness. 


\section{BACKGROUND}

\section{Educational effectiveness of simulation-based software applications}

In construction engineering education, traditional education methods are becoming challenging because their well-structured and fragmented problem sets do not effectively represent the ill-structured, complex and dynamic nature of real construction projects (McCabe et al. 2000; Sawhney et al. 2001; AbouRizk and Sawhney 1994; Rojas and Mukherjee 2005). While valuable, case studies and site visits that instructors commonly use as supplemental teaching methods are insufficient for students to develop a holistic understanding of the problem domain. According to Pennell et al. (1997), case studies used in classes are often simplified by the instructor and thus could give students the impression that construction projects are well-structured problems, typically with one correct solution. Site visits, though helpful, also allow students to see only specific activities that happen in the particular visiting period of time, and are often challenging as they involve risk and safety issues (Echeverry 1996). Thus, the fragmented and wellstructured nature of traditional lecture-based classrooms is deemed insufficient in equipping students with a conceptual framework and skills applicable to solve complex real world problems (Jonassen et al. 2006).

A different approach - learning by doing - is argued to be more effective than the traditional learning by listening and recalling information for developing abilities to both define a problem and develop solutions to the problem (Garris et al. 2002; Simon 2000; Nikolic 2011). In construction education, Betts et al. (1993) stated that active projectbased learning is a more suitable approach than traditional lectures. 
Interactive simulations and games have been long explored and used as effective educational tools to support active learning. A simulation in the educational domain is defined as a simplified model of reality or a set of abstract concepts developed for teaching purposes, predicting behaviors, or testing models and processes (Prensky 2004; Rieber 1996; Sawhney et al. 2001). Goedert et al. (2011) argue that construction simulations can be used to help students learn from real project-based experiences. Simulation modeling of real world scenarios provides a risk-free learning environment in which students can test decisions, observe outcomes, and the process many times in a relatively short time (Scott et al. 2010; Herrington and Oliver 1995). Simulations with game characteristics such as competition, goal-driven activities, risk and scoring mechanisms are referred to as simulation games - a simplified model of reality in which students compete for a certain outcome based on the set of rules and constraints (Szczurek 1982; Van Eck and Dempsey 2002; Nikolic 2011). These interactive educational simulation games are increasingly explored for their abilities to support the learning through better visualization, exploration of the problem domain, and immediate feedback in a realistic environment (Gee 2007; Ke 2009).

\section{Applications for education in construction planning and management}

To date, a large number of research efforts have been undertaken to improve the learning of construction planning and management using simulations and games. Two generations of the Virtual Construction Simulator were developed as 4D learning modules enabling students to develop construction sequences while interacting with the 3D model (Wang 2007; Jaruhar 2007). The evaluation of the VCSs demonstrated the benefit of an integrated schedule planning and reviewing which helped students visualize and better 
understand the construction planning process (Nikolic et al. 2009; Wang and Messner 2007). The remaining challenge however, was the lack of a substantial real-time feedback which students still received from the instructor during the in-class presentations. Some recent efforts include Virtual Interactive Construction Education (VICE) developed by Goedert et al. (2011) which uses modeling, simulation and visualization technologies to interactively teach construction engineering. Rojas and Mukherjee (2005) developed a conceptual framework for a general-purpose situational simulation environment for construction education and the Virtual Coach as a pilot implementation of the framework. These research efforts demonstrate the need to engage students in realistic experiential learning environments to build the skills applicable in real world projects.

Research in educational simulation games has identified pedagogical, simulation, and game attributes such as goal-driven exploration, rules, immediate feedback, interaction, challenge, and engagement to be particularly conducive to learning (Aldrich 2005; Blunt 2007; Gredler 2003; Prensky 2001; Squire 2005). Table 1 summarizes common educational simulation game features considered for the VCS3 development.

\section{Table 1 Identified features of educational simulations}

\section{DEVELOPMENT OF THE VIRTUAL CONSTRUCTION SIMULATOR (VCS3)}

The development of the VCS3 simulation game focuses on planning, creating, reviewing, and modifying construction schedules with respect to decisions made regarding resources such as labor, equipment, cost, and embedded variability. The VCS3 development 
addresses observed limitations of the previous VCS 4D learning module development, and adds specific project-based constraints to motivate students to consider the most feasible set of resources to perform work. It also allows students to revise their initial plan based on progress throughout a project. Additional attributes include immediate performance feedback, which complements the instructors' feedback that students receive in class, to encourage the exploration of different schedule solutions and their immediate outcomes. The automated calculation of activity durations supports rapid testing and comparison of different solutions. The dynamic factors such as varying labor productivity affected by weather, experience, or overtime, along with specific project based constraints and goals, aim to encourage students to iterate through solutions and learn inherent trade-offs. The following educational simulation and game features and attributes were identified to support student learning and were incorporated in the VCS3 development.

\section{Features}

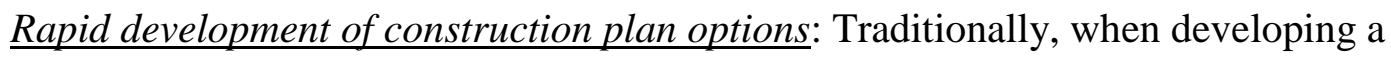
construction plan, students spend a significant amount of time manually searching for productivity and cost data through standard sources such as RS Means, to identify construction activities and methods, calculate activity durations, and develop the sequence (Nikolic et al. 2011). Minimizing labor intensive and time-consuming repetitive tasks by automating the activity duration and cost calculations allows students to experiment and test more alternatives in a much shorter time. 
Minimizing the manual input: Along with the previous feature, minimizing manual inputs reduces the possibility of errors, especially considering the experience level of the students. Replacing manual inputs with click-and-choose options ensures the consistency of the inputs for individual testing of different options.

Project-based constraints and rules: Each construction project has specific constraints such as available budget, available resources, and project deadlines. Project-based constraints are deemed critical for added realism to the simulation and for effective learning. This is one of the features applied in multiple educational tools such as VICE and Virtual Coach, and its effectiveness has been documented (Goedert et al. 2011; Rojas and Mukherjee 2005).

Goal-driven exploration: The ability to explore different strategies and compare different outcomes to meet the project goal, helps students form their mental model of the problem domain. For instance, students may select different construction methods and manage resources differently if the goal is the lowest cost compared to achieving a short schedule. By exploring different scenarios, students can learn about various trade-offs between different options.

Dynamic productivity factors: Weather, labor experience, workforce learning curve, workforce fatigue, site congestion, and resource availability are among different factors that can substantially affect construction progress. Incorporating varying productivity factors into the construction simulation can help students learn how a plan is altered and managed during the "actual" construction, adding realism to the simulation experience. Virtual Coach, Cost Control Simulation, and MERIT are examples demonstrating the 
effectiveness of dynamic factors (Rojas and Mukherjee 2005; Borcherding 1977; Wall and Ahmed 2008).

Simulating the decision-making and management for active engagement: To further add to the students' realistic experience and support learning, it is important to provide realistic scenarios about decisions involved in construction planning and management. Part of developing realistic scenarios is to define roles for students to play during the simulation process. In the VCS3, students assume the jobsite superintendent role making daily resource management and schedule decisions, and reviewing the daily progress reports to plan for the next day of the construction through project completion.

$\underline{4 D \text { visualization of construction progress: }} 4 \mathrm{D}$ visualization has demonstrated to help students intuitively understand a construction schedule (Wang 2007).

Immediate feedback: Students actively build knowledge by manipulating input variables to test assumptions, and then receiving system's feedback on the outcomes of their solutions. Understanding how construction progress and cost can be affected by various variables such as weather, resource productivity and resource management can greatly influence planning strategies and decisions to manage the construction progress. Immediate feedback is critical for students to quickly test different construction plan solutions and see the outcomes of their decisions; see the construction progress and adjust the plan accordingly. This interactivity supports active learning by engaging students with the material which is responsive to students' actions instead of passively receiving the information (Thomas 2001). 


\section{Functional Requirements}

To implement the identified pedagogical and simulation-game features, a corresponding set of functional requirements was developed (see Fig. 1).

\section{Fig. 1 Traceability matrix of the VCS3 features and the functional requirements}

Pre-defined construction activities and methods: In the VCS3, planning a construction schedule is primarily a function of choosing construction methods and resources. For each assembly type listed for a given project, students choose between possible construction methods by comparing data such as resources types, daily output, and cost. Selecting construction methods and respective crew sizes creates a pre-defined list of construction activities attached to student-created building assembly groups. Based on selected methods and crew sizes, each activity's as-planned duration is calculated automatically. This approach eliminates the laborious manual calculation of activity durations, reduces input error, ensures output consistency, and serves to motivate students to more efficiently explore alternatives for the most optimal solution. This approach also enables the instructor to more easily control the overall simulation time and ensure more focused learning.

Data management: As the majority of the construction resources, activities, and methods are shared between different construction projects, it is more efficient and beneficial to manage both shared- and project-specific data in a database, and retrieve the data effectively as needed. Also, for the purpose of adding future projects and custom learning scenarios, it is more convenient to change, reuse, and add the data when stored and managed independently in a database without making major modifications. 
Physical and activity constraints: Embedding basic activity constraints serves to reduce the error in developing a sequence and to ensure the development of a feasible schedule. Physical constraints refer to a logical physical sequence between building components. For example, a column cannot be constructed before its footing is completed. Similarly, activity constraints refer to a specific sequence of activities that should be performed in a predefined order. For instance, excavation precedes reinforcing, or formwork precedes placing concrete.

System dynamics: Factors that impact the construction progress appear to be the most challenging for students to grasp in traditional educational settings. Learning to respond to changes and delays to the construction schedules that occur due to weather, fluctuating labor productivity, congestion or other unanticipated events is difficult to understand from a standard CPM schedule or lectures. Labor productivity, for example, fluctuates depending on the weather conditions, congestion, working overtime for extended periods, or a crew's level of experience. Understanding the effect of these factors and their intricate relationships can improve the decision-making process for managing construction efficiently. To simulate these dynamic changes, the as-built schedule is calculated by using a relatively simple system dynamics model. The relationships between the schedule progress, productivity, cost, and labor utilization are dynamic and multi-directional forming a complex and a non-linear system, thus lending itself to the system dynamics approach (Pena-Mora and Park 2001). Within the system dynamics model, a direction of impact between the factors can be determined and applied to calculate the overall progress of construction. 
Interactive visualization using a graphics engine: Graphics engines such as a game engine provide useful pre-programmed functions for the developer to easily and rapidly implement required functions such as loading three-dimensional geometric models, visualizing 4D simulations, and interacting with the geometric models through predefined user interactions.

Progress report: To further support the visualization of the construction progress, a daily project report provides instant feedback on the project progress after each simulated construction day. The progress report can provide the user with detailed information about the progress for each of the activities, cost to date, and resource utilization. Based on this information, the user can make necessary decisions and adjust the plan for the remaining activities if needed.

\section{Process for construction planning and simulation}

\section{Developing a construction plan}

To develop a construction plan, the user steps through the process of grouping building components, choosing construction methods for each of the component type, planning resources, and developing the activity sequence (Fig. 2).

\section{Fig. 2 The process to develop a construction plan}

Review the project and building components: To develop the plan, the first step is to understand the construction project and project-related constraints. The user can interactively navigate a 3D model of the project and view building component properties such as material description, quantities or dimensions (Fig. 4a). The next step is to 
consider possible construction zones and group building components of the same type. To help students visualize the project and its components, the selected components are highlighted and the non-selected components become semi-transparent, allowing the selected ones to be viewed even if they are hidden behind other components.

Group building components: The user can only group building components of the same type (e.g. columns with columns, but not columns with beams) since each component type has associated construction methods. This grouping constraint is necessary in order to automatically generate and assign a set of construction methods to each building component group. This grouping process facilitates efficient construction planning when assigning construction activities to component groups.

Select construction methods: For each component type (e.g. cast-in-place footing, wood column, or truss) the user selects a construction method for each of the associated activities (Fig. 4b). For example, a cast-in-place concrete footing assembly involves excavation, formwork placement, reinforcement, concrete placement, formwork removal activity, and concrete curing. While concrete curing activity is the only continuous time activity defined to take between 10 and 12 hours to complete, each of the remaining activities can be performed using different construction methods. Once the methods for all component types are selected, the application populates all instances of the selected construction methods and assigns them to the building component group instances (Fig. 3). Thus, the user does not need to repeat the method selection for each instance of the activity set for the same building component type, resulting in faster and more reliable construction planning. 
Fig. 3 A mechanism to create activity sets (Source: Adapted from Nikolic 2011, with permission)

As mentioned earlier, instead of the user deciding on the construction activities, the list of construction activities is generated within the application. This streamlines the process of developing the construction schedule and ensures the comparability of the schedules developed between simulation runs and between different players. The automated activity creation allows students to gain a more holistic overview of the scheduling process and focus on the types of decisions involved in the plan development process rather than investing time in searching for data and manually developing and calculating the schedule. The predetermined set of activities can be both limiting and advantageous, however, this allows for customized project scenarios and a focus on specific issues depending on the learning objectives. It is important to note that teaching students how to find and calculate scheduling data can be incorporated in other class activities or assignments.

Plan resources: Students select crew sizes for each of the chosen construction methods, which are then used to calculate as-planned durations (Fig. 4c). These as-planned durations however, may change during the later construction simulation if the user decides to allocate resources differently or can be affected by various factors during the simulation mode.

Develop a sequence: In this final planning step, students develop the sequence of activities generated from the selected construction methods and resources associated with each assembly group (Fig. 4d). Activity durations are automatically calculated from the 
assembly groups' material quantity and base productivity rates associated with the selected construction method and the default crew size selected by the user.

Fig. 4 Construction plan development procedures (4a. Explore/Understand the project; 4b. Select construction methods for each activity; 4c. Allocate resources to each activity; 4d. Develop construction sequences)

\section{Simulating the project construction}

Once the students develop a construction plan, they start the simulation mode for the actual construction based on their plan. In the simulation mode, the students in the superintendent's role are responsible for hiring, allocating, and managing resources daily until the construction is complete (Figs. 5 and 6). The following are the decision steps made during the simulation process.

\section{Fig. 5 Daily simulation process}

\section{Fig. 6 Activities during simulations}

(6a. Recruit resources for the simulation day; 6b. Assign resources to the starting activity; 6c. Calculate/Update construction progress; 6d. Review the progress)

Recruit resources for each simulated day: Before each construction day starts, the student as a superintendent "hires" resources to be on the site for that day based on the list of activities planned to start (from the as-planned schedule), or are already in-progress. Resources consist of both laborers and equipment (Fig. 6a). Hiring multiple crews can accelerate each activity, if necessary, but may cause increased inefficiency depending upon follow-on activities. In this manner, the planned schedule can be altered and updated based on the resource availability and management. 
Assign resources: After the construction day starts, activities are checked against physical and activity constraints, and if both are satisfied, the application prompts the user to allocate available resources (Fig. 6b). A crew represents a resource unit and consists of the required quantity of field labor and equipment. To accelerate an activity, students can hire multiple crews. The application then checks if the user assigned all the necessary resource types and quantities to form at least one crew unit to start the activity. If not all the required resources are assigned or available, the activity waits for the next simulation iteration and again asks the user to assign resources.

Calculate work progress: Once the activity starts, the application changes the status of the activity from "Not Started" to "In-Progress" and calculates the amount of work the crew unit(s) perform for each time interval. This amount of work that has been completed is subtracted from the remaining work quantity using the progress calculation equation (1). To visualize the construction activity progress, the VCS3 decreases the transparency of the building component and shows its final texture once the component is constructed (Fig. 6c). This process is repeated for all the activities that are either not started or inprogress in the activity list. When the quantity of remaining work becomes zero, the activity status becomes "Completed." This progress calculation continues until all the construction activities are completed, or until the project completion.

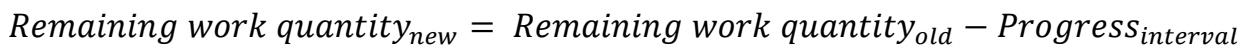

Where,

$$
\begin{aligned}
\text { progress }_{\text {interval }} & =\text { Productivity }_{\text {crew }} \times \text { Time Interval } \times \text { Productivity Factor }_{1} \times \ldots \\
& \times \text { Productivity Factor }_{n}
\end{aligned}
$$


Generate daily progress report: At the end of each simulated day, the application generates a progress report showing the information about the weather condition and its effect on the overall productivity; the construction progress and the status of each activity; daily resource utilization; and daily and cumulative labor and equipment costs (Fig. 6d).

\section{System Dynamics Model}

Fig. 7 shows the system dynamics model underlying the VCS3 development with factors identified as the most common to affect the project schedule and cost. Construction factors and their relationships have been identified and adapted from several construction productivity studies (Fulenwider et al. 2004; Neil 1982; Thomas and Raynar 1997; Thomas and Sakarcan 1994) and scoped to the level which allows for scenario based and focused learning. The metric for satisfactory project construction completion is currently defined through the project duration and cost. Productivity rate is directly affected by factors such as learning curve, overtime, congestion, and weather conditions and thus can influence the activity duration. For example, bad weather and a lack of project experience negatively impact productivity, which then influences the overall construction duration, along with the increased cost and eventually, reduced owner's satisfaction.

\section{Fig. 7 System dynamics model for the VCS3 (Nikolic 2011, with permission)}

The factors and metrics in black are implemented in VCS3 and those in gray will be implemented in the next version. The weather factor is currently modeled in two states (i.e., sunny and rainy) to demonstrate its impacts onto the construction productivity. The 
labor productivity is $100 \%$ of the RS Means productivity data for sunny weather condition, while the productivity reduces to $90 \%$ in the rainy condition, which is programmed to occur every fourth day. Some factors, such as learning curve, are modeled to follow an equation. For example, the productivity grows more rapidly at the beginning and then gradually later due to the learning curve effect. The factor is simplified into a series of multipliers as a function of time to implement in the VCS3. The productivity of a labor resource starts at $75 \%$ of the RS Means productivity value in the first hour and increases to $90 \%$ after four hours of experience. The productivity becomes $100 \%$ between four hours and 24 hours. After the time, the productivity increases to $110 \%$ to account for project experience. The compound productivity factor for each resource is currently calculated from both the learning curve value and the weather impact value. In the next development phase, the productivity factor will be calculated by taking further into account the congestion and overtime when these will be implemented.

\section{System Architecture}

To implement the simulation game features, a system architecture that consists of control modules, a data model, and corresponding user-interfaces was developed (Fig. 8). The data model represents the physical and abstract objects used in construction projects. The control modules through a series of user-interfaces guide the student to develop a construction plan and simulate the construction. The VCS3 is developed in C\# using the .NET framework and the XNA game engine to implement the system architecture.

Fig. 8 System architecture (Source: Adapted from Lee et al. 2011, @ ASCE) 


\section{Control Modules}

The control modules receive user input, process the inputs, and displays the results. The main VCS3 modules include a planning control module, a simulation control module, and a $3 D$ geometry control module.

The planning control module helps the user to interactively develop a construction plan. The module comprises a series of graphical interfaces to guide the user through the decision steps when planning the construction, and subsequently calculates the asplanned construction schedule. To efficiently support the construction planning process, the information about the construction project such as building component properties, quantities, construction methods, activities, and resources are stored and retrieved from the Microsoft Access database file. The module also enables the user to review the developed construction plan in the Microsoft Project CPM application, and revise and update the plan if desired.

The simulation control module runs daily simulations based on the simulation process using the list of construction activities and corresponding methods that the user selected; checks if activities meet physical and activity constraints; calculates construction progress; manages and executes the user's resource management strategies interactively, and generates daily progress reports.

The 3D geometry control module supports interactive navigation of the 3D model, element grouping, and 4D simulation visualization. The user can zoom in and out, select/deselect components, rotate their viewpoint, and navigate the model via various input devices. Selected components are highlighted and their properties are displayed. To 
support 3D/4D visualization and interaction, different rendering engines have useful predeveloped libraries of functions to enable quick and reliable development. The Microsoft XNA game engine was used for the VCS3 for its performance and 3D rendering quality, and its extensive set of class libraries designed to support cross-platform computer game development based on Microsoft .NET Framework 2.0.

\section{A Construction Object Model}

A simple object-oriented data model was developed to represent physical and abstract objects associated with a construction project, and can be easily expanded by adding classes of new objects (Fig. 9). The classes in the current model include BuildingElement, (labor and equipment) Resources, ConstructionActivity and Geometry. The BuildingElement class further includes child classes for building elements such as footings, slabs, columns, beams, trusses and sheathing. The Resource class has child classes for human resources, equipment resources, and crews that form a team to perform construction activities. The ConstructionActivity class defines construction activities, attributes to calculate the construction progress, and references to resource objects associated with a particular activity. Lastly, the Geometry class helps model and import 3D geometry in different formats. The Geometry defines attributes of the objects' graphical representation such as the path to the model files, texture, color and transparency. This Geometry class can be an attribute of the BuildingElement class so that the BuildingElement class has a reference pointer to render its geometric data.

Fig. 9 A data model developed for VCS3 (Lee et al. 2011, (O) ASCE) 


\section{The Pavilion Construction Project}

To demonstrate the dynamic nature and the greater level of complexity in managing construction processes, a relatively small-scope pavilion project was deemed as the most appropriate to avoid information overload. This pavilion project adapted from a real

world project comprises of work packages such as cast-in-place foundations, a slab, wood columns, beams, trusses, sheathing, and shingles. The pavilion project also allows the students to play several simulation runs in a relatively short time (about 15 to 20 minutes per cycle), which is critical when the class time is limited. The information about human and equipment resources are adapted from both the case study and the standard productivity data source such as RS Means.

\section{Program verification and validation}

Following the conversion of the system dynamics model into a computational simulation model, the simulation model underwent a verification process in which the simulation was checked for both its internal and external representational validity. Internal validity refers to the simulation game functionality and whether the model complies with the initial list of assumptions. For consistent and reliable application performance, each simulation step output was manually calculated to check the simulation model for accuracy, and in repeated simulation runs all outputs were checked for consistency.

External representational validity refers to how closely the simulation model behaves and corresponds to its relevant real world experience. External validity thus refers to appropriate inclusion of identified construction factors and decision processes found on real construction projects. The validation process sought to ensure that specified 
information in a learning scenario was included in the computational model. Three faculty members in construction and two industry practitioners reviewed the simulation model to ensure that the factors are relevant and valid. As more factors are implemented in future versions of the VCS, additional external validity testing will be implemented.

\section{EVALUATION}

To evaluate how effectively the VCS3 simulation game contributes to learning and motivation, a one-group pretest-posttest design was conducted in a third-year course with an annual enrolment of approximately hundred students, and a graduate level course. Students in the third year introductory course to the building industry (AE 372) were selected for the study because of their relatively little practical experience on construction sites, as well as their limited knowledge of construction scheduling and management concepts. Measuring the educational effectiveness focused on the extent to which the learners' knowledge has changed or improved due to the effect of the simulation game, as well as whether students' motivation to learn has improved. The VCS3 was implemented during a two-hour practicum session. Data was collected through online pre- and postsurvey questionnaires with both open-ended and Liker-scale items measuring the level of learning, motivation, and students' perception of the simulation experience and the VCS3 application use (Nikolic et al. 2010). In addition to the simulation assignment, a focus group discussion was conducted with students from the graduate level course, where students were debriefed on their learning experience.

The Kirkpatrick's framework of four levels of learning (Kirkpatrick and Kirkpatrick 2006) was used to develop the learning assessment and evaluation questions about cognitive 
and motivational effects. The cognitive portion aimed to measure any difference in understanding, interpreting, or acquiring of new information as a result of the simulation experience. The open-ended format for these questions was deemed the most appropriate for students to reflect on specific construction issues that pertain to general construction management domains and were also relevant to the simulation exercise.

\section{The implementation procedure}

A two-hour practicum session was used for the simulation exercise, during which time students were asked to develop and simulate the project sequence for the pavilion using the VCS3 application, submit the assignment handout, and complete the pre- and posttest questionnaires. The assignment asked students to test and report how fast they could build the pavilion under given constraints, including budget and available resources. Although completing the assignment was a class requirement, the participation in the study and the completion of surveys was voluntary. Within the first hour of the practicum session, most students were able to run three or four simulation cycles. Few students decided to stay longer for additional tries to achieve better results. Once the students finished their exercise, the students were asked to complete a post-test survey.

\section{Results}

In the third-year course, out of 97 student participants, 85 students completed the pre-test survey; 81 students completed the post-test survey; and 87 students submitted the handouts. The average age of the participants was 21; there were 62 male and 23 female students. All Likert-scale items were statistically analyzed and the content analysis was used for all open-ended items with the inter-rater reliability of $84 \%$ level of agreement. 
In meeting the learning objectives, students demonstrated an increase in knowledge about the construction planning process and the ability to identify changes and challenges in the efficient management of the construction process and resources. The indication that experiential learning took place during the simulation exercise was reflected in the students' responses to construction-related questions, which were more detailed and interpretative after the simulation, based on what they observed (Nikolic 2011). Furthermore, the learning process that took place during the simulation exercise was indicated by the managerial challenges students identified, such as coordinating activities start time and allocating resources. For example, realizing that curing concrete prevents other activities to start for a period of time, causing resources to wait and thus loosing time and money, students used strategies to start the concrete pour activity towards the end of the day so that curing could occur overnight.

Learning from mistakes is recognized as a more effective and memorable experience; however, at the same time students largely demonstrated a low tolerance for what they recognize as mistakes. In the VCS3 case, the absence of the "undo" button caused challenges for students who found it easier to start a new simulation run, rather than aim to make up for any poor decisions made during the early stages of a simulation run. The habit students have to easily undo actions in various other computer applications should be addressed from the context of a real construction site where decisions and actions cannot be easily altered without a set of other related issues.

Because this study focused on the formative evaluation of the learning process supported by simulation games, students' performance on the assignment was not part of the 
learning assessment. However, the analysis of students' handouts revealed that students' reported time to build pavilion ranged from the fastest time of 4 days to 12 days. The more open exploration of the learning scenario lacked a reference to a standard duration and thus the room for further optimization. This was changed in the implementation with the graduate production management course students who had on average 1.3 years of experience and were asked to build the pavilion in no more than 6 days while staying within the budget. While the more constrictive project goal helped to focus strategies to meet the goal, students reflected on the time/cost tradeoffs when allocating more crews to accelerate activities, and contended that planning the schedule was comparatively easier than actually managing and ensuring the project is constructed efficiently given the changes that were occurring.

While the learning assessment has some limitations, the findings revealed that the students overall recognized the dynamic nature of a construction project through changes that occur to their as-planned schedule due to factors such as weather or labor productivity. All implementations to date yielded similar appraisal of the simulation experience as visual, realistic, hands-on and fun, with the benefit of being able to test different decisions and see the outcomes very quickly. At the same time, extensive learning gains were difficult to detect because of the limited number of system dynamic factors implemented at this stage. For that reason, the objective learning measurement items could not include information that was not covered by the VCS3 simulation game. 


\section{Application-Related Challenges}

While the experience of using the VCS3 was overwhelmingly rated as positive, several performance-related challenges were identified. The most frequently cited challenges included a slow simulation speed, lack of an "undo" and "save" functions, and occasional error messages during the simulation. Before the next implementation, we identified that frequent reading and writing of data to the Microsoft ACCESS database slowed the application speed. The problem was fixed by loading the data into memory when the simulation mode starts, and then uploading any updates to the database file when a daily simulation ends. The "undo" function as mentioned earlier was not implemented to reflect real world situations. Most "mistakes" students realized included not hiring enough resources for the activity scheduled to start on the simulation day and thus they wanted to redo the resource hiring, which was not allowed. The error messages were continuously collected and debugged before the following implementations.

\section{Future improvement}

Areas identified for continued improvement include functions, content, and user-interface. The "Save" function was identified as necessary for future VCS iterations to allow students to stop the simulation and resume at a later time, especially once larger projects and more learning scenarios are added. More dynamic resource allocation and adding available crews to the activities that are in progress have also been identified as a functionality that should be incorporated. Currently, once the activity is in progress, it is locked in terms of the number and type of resources assigned. 
Scaffolding has also been identified as one of the critical elements to support learning in simulation game environments. The next VCS development will thus incorporate more comprehensive and informative performance metrics, helpful tips and explanations, and different levels of difficulty.

Among other identified improvements in the user interface, the most critical ones include the ability to see the planned daily budget and up-to-date budget before the daily simulation starts so that the students can better manage the daily costs; ability to visually compare the as-planned and as-built schedule; ability to change the sequence and construction methods for activities that have not started; or seeing the weather forecast before the simulation starts so that the students can plan activities accordingly.

\section{CONCLUSIONS}

A framework for developing a simulation-based educational application to teach students dynamic construction planning and management was presented, along with the proof-ofconcept prototype application named Virtual Construction Simulator 3 (VCS3) based on the framework. Continuing the development efforts of the VCS 1 and 2, the VCS3 teaches students to develop construction plans by choosing construction methods; automates the activity duration calculation and reduces the time to develop construction plans; and incorporates dynamic factors triggered in the simulation mode in which weather and labor experience affect labor productivity. The functionality and simulation game attributes such as feedback, variability, scenario-based exploration and role-play engage students in an active and interactive environment to learn about the dynamic nature of construction planning and management and the difference between the as- 
planned and as-built schedules. The implementation of the VCS3 demonstrated its value in providing a visual, interactive, realistic and engaging learning experience. The simulation experience was rated as relevant and applicable in the construction domain. The VCS3 demonstrated the potential to enhance the students' knowledge of cost and time tradeoffs, challenges of efficient resource management, as well as factors that affect construction progress. Features such as automated cost and time calculations, which allow quick testing of different strategies and development of alternative plans, together with a defined project goal confirmed to be critical for more focused and effective learning.

\section{ACKNOWLEDGEMENTS}

The authors are grateful to Lorne Leonard and George Otto for their immense help during the development of the VCS 3. The authors thank the National Science Foundation (Grant \#0935040) for support of this project. Any opinions, findings, conclusions, or recommendations expressed in this paper are those of the authors and do not necessarily reflect the views of the National Science Foundation.

\section{REFERENCES}

AbouRizk, S., and Sawhney, A. (1994). "Simulation and gaming in construction engineering education.” ASEE/C2E2/C2EI Conference, Edmonton, Alberta.

Aldrich, C. (2005). Learning by Doing. A comprehensive Guide to Simulations, Computer Games, and Pedagogy in e-Learning and Other Educational Experiences. John Wiley and Sons, Inc., Pfeiffer, San Francisco, CA. 
Betts, M., Richard Liow, S.J., and Pollock, R.W. (1993). "Different Perceptions of Importance of Educational Objectives." Journal of Professional Issues in Engineering Education and Practice, 119(3), 317-327.

Blunt, R. (2007). “Does Game-Based Learning Work? Results from Three Recent Studies."

Borcherding, J.D. (1977). “Cost Control Simulation and Decision Making.” Journal of the Construction Division, 103(4), 577-591.

Echeverry, D. (1996). "Multimedia-based instruction of building construction." Proceedings of $3^{\text {rd }}$ Congress on Computing in Civil Engineering, ASCE, Reston, VA., 972-977.

Fulenwider, M., Helmes, P., Mojtahedzadeh, M., and MacDonald, R. (2004).

"Operational labor productivity model." 22nd International Conference of the System Dynamics Society, Oxford, England. Available at http://www.systemdynamics.org/conferences/2004/SDS_2004/PAPERS/395FUL EN.pdf.

Garris, R., Ahlers, R., and Driskell, J. E. (2002). "Games, Motivation, and Learning: A Research and Practice Model." Simulation Gaming, 33(4), 441-467.

Gee, J. P. (2007). "What video games have to teach us about learning and literacy." New York : Palgrave Macmillan, 2007.

Goedert, J., Cho, Y., Subramaniam, M., Guo, H. and Xiao, L. (2011). “A framework for Virtual Interactive Construction Education (VICE).” Automation in Construction, 20(1), 76-87. 
Gredler, M. . (2003). "Games and Simulations and their Relationships to Learning." Educational Technology Research and Development, 21, 571-582.

Herrington, J., and Oliver, R. (1995). "Critical Characteristics of Situated Learning: Implications for the Instructional Design of Multimedia." Learning with technology, J. P. A. Ellis, ed., Parkville, Vic: University of Melbourne., 235-262.

Jaruhar, S. (2007). "Development of interactive simulations for construction engineering education." Master’s Thesis, The Pennsylvania State University, University Park, PA, USA.

Jonassen, D., Strobel, J., and Lee, C. B. (2006). "Everyday problem solving in engineering: lessons for engineering educators." Journal of Engineering Education, 95(2), 1-14.

Ke, F. (2009). "A qualitative meta-analysis of computer games as learning tools." In Handbook of research on effective electronic gaming in education. Information Science Reference, R. E. Ferdig, ed., Retrieved on August 2010 from: http://www.igi-global.com/downloads/excerpts/7960.pdf, 1-32.

Kirkpatrick, D., and Kirkpatrick, P. (2006). Evaluating Training Programs. 3rd ed. San Francisco, CA: Berrett-Koehler Publishers, Inc.

Lee, S., Nikolic, D., Messner, J.I., Anumba, C.J. (2011). “The Development of the Virtual Construction Simulator 3: An Interactive Simulation Environment for Construction Management Education.” Proceedings of 2011 ASCE International Workshop on Computing in Civil Engineering, Miami, FL, USA, 454-461. 
McCabe, B., Ching, K.S., and Savio, R. (2000). "STRATEGY: A construction simulation environment." Proceedings of $6^{\text {th }}$ Construction Congress VI, Orlando, FL, USA, 115-120.

Neil, J. M. (1982). Construction cost estimating for project control, Prentice-Hall, Inc., Englewood Cliffs, NJ.

Nikolic, D., Lee, S., Messner, J. I., and Anumba, C. J. (2010). “The Virtual Construction Simulator: Evaluating an educational simulation application for teaching construction management concepts." Proceedings of the 27th International Conference on Applications of IT in the AEC Industry \& Accelerating BIM Research Workshop, Cairo, Egypt.

Nikolic, D., Jaruhar, S., and Messner, J. I. (2011). "Educational Simulation in Construction: Virtual Construction Simulator.” Journal of Computing in Civil Engineering, 25(6), 421-429.

Nikolic, D. (2011). "Evaluating a Simulation Game in Construction Engineering Education: The Virtual Construction Simulator 3." Ph.D. Thesis, The Pennsylvania State University.

Pena-Mora, F., and Park, M. (2001). "Dynamic planning for fast-tracking building construction projects." Journal of Construction Engineering and Management, 127(6). 445-456.

Pennell, R., Durham, M., Ozog, C., and Spark, A. (1997). "Writing in context: Situated learning on the web." Proceedings of $14^{\text {th }}$ annual ASCILITE conference, Perth, 
Western Australia, 463-469. Retrived From:

http://www.ascilite.org.au/conferences/perth97/papers/Pennell/Pennell.html.

Prensky, M. (2004). "Interactive pretending: an overview of simulation." Retrieved on March 2008 from: www.marcprensky.com/writing/PrenskyInteractive_Pretending.pdf.

Prensky, M. (2001). Digital Game-Based Learning. New York: McGraw-Hill

Rieber, L. P. (1996). "Seriously considering play: designing interactive learning environments based on the blending of microworlds, simulations, and games." Educational Technology Research and Development, 44(2), 43-58.

Rojas, E. M. and Mukherjee, A. (2005). “General-Purpose Situational Simulation Environment for Construction Education." Journal of Construction Engineering and Management, 131(3), 319-329.

Sawhney, A., Mund, A., and Koczenasz, J. (2001). "Internet-based interactive construction management learning system." Journal of Construction Education, 6(3), 124-138.

Scott, D., Mawdesley, M., and Long, G. (2010). "Simulation for education in construction and construction management - IT or not IT." Proceedings of the International Conference on Computing in Civil and Building Engineering, Nottingham, UK, W.Tizani, ed.

Simon, H. A. (2000). "Observations on the sciences of science learning." Journal of Applied Developmental Psychology, 21(1), 115-121. 
Squire, K. (2005). “Changing The Game: What Happens When Video Games Enter the Classroom?" Innovate 1 (6), 2005 - academiccolab.org http://www.academiccolab.org/resources/documents/Changing\%20The\%20Game -final_2.pdf.

Szczurek, M. (1982). "Meta-analysis of simulation games effectiveness for cognitive learning," Ph.D. dissertation, Indiana University.

Thomas, R. (2001). "Interactivity and simulation in e-Learning." MultiVerse Solutions Ltd.

Thomas, H. R., and Raynar, K. A. (1997). "Scheduled overtime and labor productivity: quantitative analysis." Journal of Construction Engineering and Management, 123(2), 181-188.

Thomas, H. R., and Sakarcan, A. S. (1994). "Forecasting labor productivity using factor model." Journal of Construction Engineering and Management, 120(1), 228-239.

Van Eck, R., and Dempsey, J. (2002). "The effect of competition and contextualized advisement on the transfer of mathematics skills in a computer-based instructional simulation game." Educational Technology, Research and Development, 50(3), $23-41$.

Wall, J. and Ahmed, V. (2008). "Use of a simulation game in delivering blended lifelong learning in the construction industry - Opportunities and Challenges." Computers \& Education, 50, 1383-1393.

Wang, L. (2007). "Using 4D modeling to advance construction schedule visualization in engineering education," Master's Thesis, The Pennsylvania State University. 
Wang, L., and Messner, J. I. (2007). "Virtual Construction Simulator: A 4D CAD Model Generation Prototype." Proceedings of 2007 ASCE Workshop on Computing in Civil Engineering, Pittsburgh, PA. 